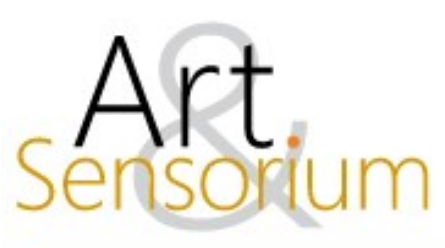

\title{
CONTRIBUIÇÃO AO ESTUDO DA TALHA LUSO-BRASILEIRA: OS RISCOS DO ACERVO DO MUSEU DA INCONFIDÊNCIA, EM OURO PRETO. \\ DOI: https://doi.org/10.33871/23580437.2020.7.2.067-081
}

Aziz José de Oliveira Pedrosa ${ }^{1}$

\begin{abstract}
Resumo: A ornamentação interna dos templos religiosos erguidos em Minas Gerais, no decorrer do século XVIII e das primeiras décadas dos oitocentos, exigiu o empenho de profissionais dedicados a elaborar relevos talhados em madeira, que tinham como fim transformar os ambientes internos das edificações, recobrindo retábulos e paredes para estabelecer a plasticidade inexistente na austera alvenaria. Embora reconhecida a operação dos oficiais envolvidos no planejamento e na execução dessas obras, persistem indagações sobre o processo de concepção dos projetos ornamentais, materializados em representações gráficas, comumente conhecidas em língua portuguesa, como os riscos que testemunham a etapa antecedente à fábrica dos serviços. Nesse sentido, o artigo que se apresenta tem como orientação interpor novos elementos para a compreensão do universo projetual da talha luso-brasileira, a partir da análise de três desenhos, ainda não examinados pela história da arte, localizados no Museu da Inconfidência (Ouro Preto), idealizados para subsidiar a confecção de um retábulo, um detalhe ornamental e um castiçal.
\end{abstract}

Palavras-chave: Riscos; Talha; Arte luso-brasileira.

\section{CONTRIBUTION TO THE STUDY OF LUSO-BRAZILIAN CARVING: DRAWINGS FROM THE COLLECTION OF THE MUSEU DA INCONFIDÊNCIA IN OURO PRETO.}

Abstract: The internal ornamentation of religious temples built in Minas Gerais during the 18th century and the first decades of the 1800s required professionals to create reliefs carved in wood that had the objective of transforming the internal spaces of buildings, covering retables and walls to produce shapes non-existent in austere masonry. Although the performance of the men involved in planning and carrying out these works is recognized, there are some questions about the design process of ornamental projects displayed in representations commonly known in Portuguese as riscos (drawings) that show the stage prior to the production. In this sense the present article aims to suggest unknown elements for the understanding of the system of the Luso-Brazilian carving project from the analysis of three drawings not yet studied by Art History, which are in the Museu da Inconfidência (Ouro Preto), designed to make a retable, an ornamental detail and a candlestick.

Keywords: Drawings; Carving; Portuguese-Brazilian Art.

\footnotetext{
${ }^{1}$ Bacharel em Design. Especialista em História e Cultura da Arte. Mestre e Doutor em Arquitetura e Urbanismo. Pósdoutorado em Arquitetura e Urbanismo. Leciona a disciplina de História Crítica da Arte e do Design na Universidade do Estado de Minas Gerais. http://lattes.cnpq.br/0720460298410665. https://orcid.org/0000-0003-4274-1096. azizpedrosa@yahoo.com.br

R. Inter. Interdisc. Art\&Sensorium, Curitiba, v.7, n.2, p. 067 - 081 Jul.- Dez. 2020
} 


\section{CONTRIBUCIÓN AL ESTUDIO DE LA TALLA LUSO-BRASILEÑA: LOS DIBUJOS DE LA COLECCIÓN DEL MUSEU DA INCONFIDÊNCIA, EN OURO PRETO.}

Resumen: La ornamentación de los templos religiosos construidos en Minas Gerais, durante el siglo XVIII y las primeras décadas de los ochocientos, requirió el compromiso de profesionales dedicados a la elaboración de relieves tallados en madera, que tenían como fin transformar los espacios interiores de las edificaciones, cubriendo retablos y paredes para establecer la plasticidad inexistente en la albañilería austera. Aunque se reconoce la operación de los hombres involucrados en la planificación y ejecución de dichos trabajos, quedan preguntas sobre el proceso de dibujo de proyectos ornamentales, materializados en representaciones comúnmente conocidas en portugués como riscos, que atestiguan la etapa anterior a la producción de los servicios. En este sentido, el artículo que se presenta tiene como orientación interponer nuevos elementos para la comprensión del universo proyectivo de la talla luso-brasileña, a partir del análisis de tres dibujos, aún no estudiados por la historia del arte, ubicados en el Museu da Inconfidência (Ouro Preto), dibujados para apoyar la fabricación de un retablo, un detalle ornamental y un candelabro.

Palabras clave: Dibujos; Talla; Arte Luso-brasileña.

\section{Notas iniciais}

No decorrer do século XVIII e no início do XIX, o ambicioso processo de exploração mineral, na então Capitania de Minas Gerais, favoreceu relevante ciclo de prosperidade econômica, política, social e cultural local. Deve-se tal fato ao surgimento e à expansão de núcleos urbanos, onde se apinhava a população e cuja vida gravitava em função das riquezas projetadas pela abundância das jazidas de ouro e de diamante. Dentre os inúmeros aspectos que caracterizam o prosperar da sociedade coeva, verificados também em grande área do território colonial luso-brasileiro, destacase a produção arquitetônica religiosa, quando templos foram erguidos para acolher as celebrações de grupos cada vez mais numerosos nessas regiões. Exemplificam esse decurso as centenas de igrejas e de capelas que delineiam a paisagem das cidades mineiras de Ouro Preto, Mariana, São João del-Rei, Tiradentes, Sabará e Diamantina.

Relevantes aspectos assinalaram a edificação dos templos erguidos em Minas Gerais, entre os séculos XVIII e meados do XIX, sobressaindo-se a produção da ornamentação destinada a cobrir os tetos e as paredes brancas, vislumbrando transformar o interior da caixa arquitetônica em ambientes cenográficos modificados pela pintura, pelos retábulos e pelos relevos esculpidos em madeira, repletos de mensagens codificadas em referências iconográficas que, além de delinearem o teatro sacro, convertiam-se em texto suscetível de auxiliar a catequese das pessoas que frequentavam esses espaços.

Nesse espectro, a talha tornou-se testemunha fundamental da produção artística mineira. Em função disso, ela tem sido objeto de análise em diversas publicações, como as de Bazin (1983), Oliveira (2003), Bohrer (2015) e Pedrosa (2019). Esses autores dedicaram-se a examinar as características formais, iconográficas e estilísticas de exemplares confeccionados desde o final do século XVII até meados do XIX. Entre as questões debatidas nessas e em outras publicações que abarcaram a temática, surgiram indagações, por vezes sem respostas, a respeito dos procedimentos técnicos que delimitavam a construção das peças retabulares e dos demais ornamentos esculpidos em madeira, posto que há menções recorrentes nos registros primários descrevendo a existência de riscos ${ }^{2}$ que subsidiavam as negociações dos serviços a serem executados, utilizados pelos contratantes e pelos

\footnotetext{
${ }^{2}$ O Dicionário técnico considera o risco como “[...] linha, traço feito com lápis ou outro instrumento. Toma-se também em concreto significando o projecto em desenho de uma qualquer obra de arte." (RODRIGUES, 1876, p. 330). Nos documentos referentes à produção da talha em Minas Gerais, encontram-se referências ao risco, à traça e, menos comum, ao debuxo. Logo, neste texto, serão utilizados como sinônimos os termos: riscos, traças, desenhos e projetos.

R. Inter. Interdisc. Art\&Sensorium, Curitiba, v.7, n.2, p. 067 - 081 Jul.- Dez. 2020
} 
contratados até o momento de louvação ${ }^{3}$ da obra efetuada. Na ampla documentação disponível nos arquivos de Minas Gerais, sejam de propriedade das igrejas ou de instituições públicas, apura-se que a confecção de retábulos e de itens talhados em madeira tinha como ponto de partida a veiculação de editais em que eram firmadas as condições dos serviços, os prazos de execução e a expressa observação de se seguir os riscos definidos e apresentados previamente ao ato de arrematação dos trabalhos, pois esses desenhos esclareciam os objetos que se pretendia realizar. Para exemplificar, cita-se o processo decorrente da fiação do retábulo-mor da igreja Matriz de Nossa Senhora do Bom Sucesso (Caeté), em que essas informações são devidamente arroladas.

\begin{abstract}
Termo de fiansa que fazem o Cap.m Joaõ de Souza Lix. ${ }^{a}$ e M.el Fr.co Lix.., por Jozé Coelho de Noronha a obra detalha da capela mor de V.a Nova da Raynha, na forma das condisoens lançadas a f. 85 do L.o do Reg.o de ordens, deq.e se procede arrematação neste L.o a p. 104. Aos vinte cuatro dias do mês de agosto de mil setecentos e sessenta anos nesta Vila Rica de Nossa Senhora do Pilar do ouro preto na caza dos Contos e fazenda Real em au digo Real, aparecerão presentes com suas próprias [?] do Cap. m João de Souza Lisboa, Manuel Francisco Lisboa moradores nesta dita e por eles foi dito que de livre e espontânea vontade sem constrangimento de prova algua ficarao com efeito ficao por fiadores, principaes pagadores de Jozé Coelho de Noronha do pe de juízo, arrematação da obra do retabolo da Capela mor da vila nova da Ray nha na forma do termo de rematação e condisoes lançadas nos atos declados no titulo deste termo pelo qual como dito se obri digo dito tem [?]se obrigao aque odito seu fiador [ilegível] adita obra na forma das ditas condisoes e risco, e não o fazendo assim ficarem reposaveis abonar o prejuízo que a fazenda Real do contrario receber; sendo presentes (...). (ARQUIVO PÚBLICO MINEIRO. Livro de arrematações de contratos e ofícios públicos a cargo da Provedoria da Real Fazenda em Vila Rica -1744-1765, fl. 127).
\end{abstract}

No universo artístico colonial luso-brasileiro, os riscos eram representações gráficas equivalentes às plantas arquitetônicas, contendo informações necessárias para execução dos retábulos. Neles eram expressas dimensões, escalas, ornamentos, estruturas e demais referências essenciais para a execução do trabalho. É sabido que a produção desses desenhos era de responsabilidade de artífices

[...] que detinham conhecimento no campo da arquitetura e da arte da talha, conheciam as relações de proporção, simetria, técnicas de representação, o repertório ornamental corrente e eram habilitados a reproduzir elementos arquitetônicos, figuras antropomórficas e todas as formas que, tradicionalmente, compuseram o objeto retabular (PEDROSA, 2019, p. 120).

Embora a existência desses riscos seja correntemente aludida na documentação, raramente eles são encontrados. É plausível que estivessem depositados nos arquivos, juntamente com os papeis relativos ao processo de início da obra de talha, marcado pelo ato de arrematação, até a sua conclusão, que poderia abranger sequências de ordens de pagamentos pelos serviços processados ou listas de problemas comumente decorrentes desses trabalhos, como exemplifica a querela em que se envolveu o entalhador José Coelho de Noronha, frente aos impasses resultantes da produção do retábulo de São Miguel, na Sé de Mariana (PEDROSA, 2013). A raridade desses projetos sinaliza que os riscos não eram a fração mais valorizada no encadeamento das operações de confecção da ornamentação, pois valores irrisórios eram pagos aos homens que realizaram essas traças, em contraponto às elevadas quantias recebidas pelos oficiais encarregados pela execução, que

\footnotetext{
${ }^{3}$ Louvação: "Parecer ou laudo expedido pelo louvado designado para avaliação de determinada obra." (ÁVILA; GONTIJO; MACHADO, 1996, p. 60).

R. Inter. Interdisc. Art\&Sensorium, Curitiba, v.7, n.2, p. 067 - 081 Jul.- Dez. 2020
} 
alcançavam riqueza e notoriedade, muitas vezes eclipsando o nome daquele que elaborou o desenho (PEDROSA, 2019). A documentação nem sempre relacionava quem foram os artífices que desenvolveram esses projetos. A autoria costumava ser atribuída ao executor, deixando oculta a identidade do mentor intelectual da traça (PEDROSA, 2019).

Distingue-se a existência de inúmeros registros históricos referentes à produção da talha ornamental mineira, porém, é incomum localizar as traças que subsidiaram a elevação desses trabalhos, faturados entre os séculos XVIII e XIX. Pesquisas conseguiram identificar alguns riscos ${ }^{4}$, destacando-se o projeto depositado no Arquivo Histórico Ultramarino (Lisboa) ${ }^{5}$, de autoria desconhecida, com direções para elevação do retábulo-mor da igreja Matriz de Santo Antônio (Itaverava). De acordo com as pesquisas de Bohrer (2015), no espólio da Torre do Tombo (Lisboa), há um desenho, não concretizado, para o retábulo-mor da igreja Matriz de Santo Antônio (Glaura). Outro exemplar foi apresentado por Oliveira (2003), que localizou, no Arquivo do Instituto do Patrimônio Histórico e Artístico Nacional - IPHAN (Rio de Janeiro), uma imagem de traça retabular, cujas parcas informações obtidas não permitem delimitar qual templo receberia o projeto, tampouco se ela está relacionada à edificação religiosa alocada em Minas Gerais. Por último, menciona-se o interessante traçado de 1789, consoante a pesquisa de Gutierrrez (2016), que se encontra na parede do consistório da igreja de Nossa Senhora do Carmo (Ouro Preto), elaborado em tamanho natural, esboçando um presumível objeto retabular a ser produzido para o interior da igreja, cuja formulação pode ter sido motivada para amparar reflexões sobre a obra a ser desenvolvida.

Os registros imagéticos supramencionados são profusamente conhecidos, pois foram analisados em publicações dispostas a debater os mecanismos que subsidiaram a execução da talha mineira, como relacionado anteriormente. No entanto, não se conhecem representações gráficas análogas e suscetíveis de alargar considerações sobre o protagonismo exercido por elas nos procedimentos que antecediam e determinavam a confecção dos relevos ornamentais em madeira, materializados, principalmente, em retábulos que preenchem os ambientes internos dos templos coloniais lusobrasileiros. Fortuitamente, a investigação que embasou este texto identificou, no repositório do Museu da Inconfidência (Ouro Preto), três interessantes desenhos com um risco para retábulo, ${ }^{6}$ um croqui para dossel ${ }^{7}$ e um esboço para castiçal ${ }^{8}$. Reconhecida a importância desses documentos para o exame da talha luso-brasileira, não localizados estudos relacionados às peças em debate e considerada a singularidade de se encontrar testemunhos dessa natureza, este artigo tem como finalidade apresentar esses três desenhos, para que eles possam suscitar pesquisas destinadas a examinar a produção da escultura ornamental colonial. Para tanto, serão relacionados os dados históricos encontrados, procedida a análise formal das peças que se pretendia confeccionar e apresentadas observações que possibilitaram detectar a materialização de um desses projetos, provavelmente alocado na igreja de Nossa Senhora das Mercês (Ouro Preto).

\footnotetext{
${ }^{4}$ Ver: GUTIERREZ; RAMOS, Adriano. Francisco Vieira Servas e o ofício da escultura na capitania das minas do ouro. Belo Horizonte: Instituto Cultural Flávio Gutierrez, 2002, p. 109.

5 ARQUIVO HISTÓRICO ULTRAMARINO: Instituto de Investigação Científica Tropical. Minas Gerais, PT/AHU/CARTM/011/01168.
}

6 MUSEU DA INCONFIDÊNCIA. Desenho Arquitetônico. Ouro Preto. Disponível em: $<$ http://museudainconfidencia.acervos.museus.gov.br/acervo-museologico/desenho-arquitetonico-5/>. Acesso em: 20 abr. 2020.

${ }^{7}$ MUSEU DA INCONFIDÊNCIA. Dossel para a igreja Nossa Senhora das Dores, Ouro Preto. Ouro Preto. Disponível em: <http://museudainconfidencia.acervos.museus.gov.br/acervo-museologico/desenho-arquitetonico-6/>. Acesso em: 20 abr. 2020.

MUSEU DA INCONFIDÊNCIA. Risco Castiçal. Ouro Preto. Disponível em: < http://museudainconfidencia.acervos.museus.gov.br/acervo-museologico/desenho-documental/>. Acesso em: 20 abr. 2020.

R. Inter. Interdisc. Art\&Sensorium, Curitiba, v.7, n.2, p. 067 - 081 Jul.- Dez. 2020 


\section{Os riscos}

Constam, entre os itens do acervo do Museu da Inconfidência, três riscos: um desenho para um retábulo, um para dossel e outro para castiçal que, indiscutivelmente, são relevantes testemunhas sobre a história da talha no território colonial luso-brasileiro. Embora seja expressiva a existência desses registros, são escassas as informações referentes à autoria, ao destino e à sua efetiva realização. Tais esclarecimentos contribuiriam para melhor avaliar esses documentos e equacionar as relações entre projeto e execução, haja vista que alterações eram processadas no decorrer da consumação dessas peças, como esclarece o procedimento de elevação do retábulo-mor da igreja Matriz ouro-pretana de Nossa Senhora do Pilar (1746-1754), em que o entalhador Francisco Xavier de Brito promoveu transformações na traça inicial ${ }^{9}$. Exceto o desenho para dossel, que está acompanhado da identificação de origem e da data de elaboração, as outras duas traças não expõem referências complementares, tampouco apontam a região para a qual foram pensadas, se para algum templo de Minas ou de outra Capitania brasileira.

Diante de tudo isso, é fundamental examinar as peças localizadas para que se possam discernir detalhamentos, nem sempre pontuados em documentação. Inicia-se essa inspeção a partir da traça para retábulo, cuja ficha catalográfica do Museu da Inconfidência ${ }^{10}$ acusa ser item incorporado ao acervo da instituição no ano de 1986. As dimensões do formato são de $42,7 \mathrm{~cm}$ de altura por $30,8 \mathrm{~cm}$ de largura; a representação foi realizada em nanquim, com sombreados que lhe conferem o caráter volumétrico; não foi detectado o autor; não há datação. Nota-se que o desenho apresenta sistematização corriqueiramente empregada em projetos retabulares, em que foi debuxada metade da peça para expressar os aspectos plásticos ${ }^{11}$, considerando-se a simetria do conjunto. No outro lado, há informações técnicas e pormenores da estrutura, a fim de auxiliar a fatura. É ausente a planta baixa, que pode ter sido inserida em outra folha integrante do projeto, não encontrada. Nessas traças, observa-se que era frequente a presença da projeção superior, relacionando a distribuição de colunas, mesa do altar, camarim e outros elementos que deveriam ser posicionados no momento da construção, posto ser o retábulo uma composição tridimensional, com itens organizados em planos diferentes, para proporcionar a percepção espacial arquitetônica do conjunto (Figura 1).

\footnotetext{
9 ARQUIVO DA PARÓQUIA DE NOSSA SENHORA DO PILAR. Livro de Termos da Irmandade do Santíssimo Sacramento, 1729-1777, v. 224, fl. 57.

${ }^{10}$ MUSEU DA INCONFIDÊNCIA. Desenho Arquitetônico. Ouro Preto. Disponível em: $<$ http://museudainconfidencia.acervos.museus.gov.br/acervo-museologico/desenho-arquitetonico-5/>. Acesso em: 20 abr. 2020.

11 Exemplo: risco para o retábulo da igreja Matriz de Santo Antônio (Itaverava). ARQUIVO HISTÓRICO ULTRAMARINO: Instituto de Investigação Científica Tropical. Minas Gerais, PT/AHU/CARTM/011/01168.

R. Inter. Interdisc. Art\&Sensorium, Curitiba, v.7, n.2, p. 067 - 081 Jul.- Dez. 2020
} 


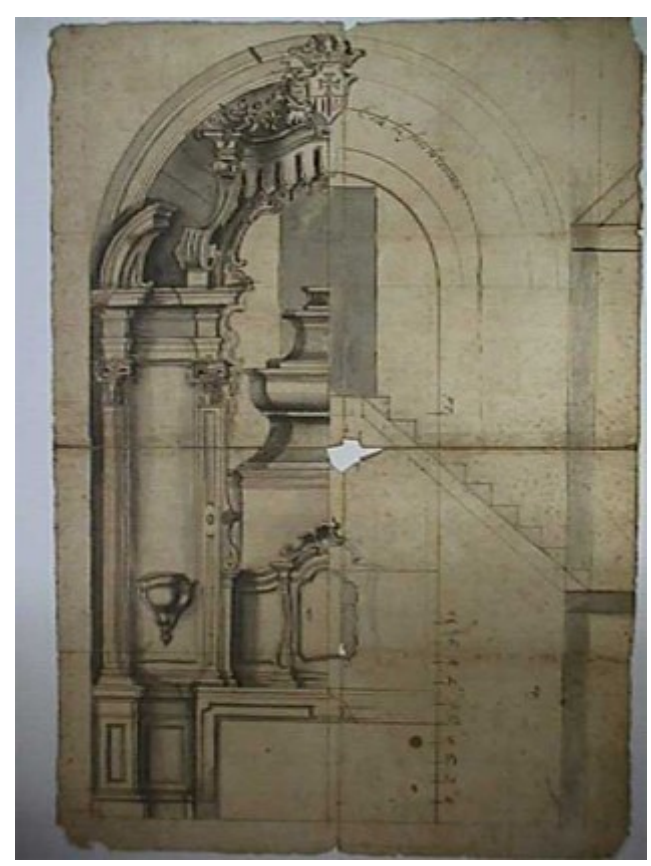

Figura 1 - Risco para retábulo.

Fonte: Museu da Inconfidência, Ouro Preto ${ }^{12}$.

O desenho é composto por base com molduras geométricas, delimitando áreas de apoio às colunas, e os tramos externos estão projetados à frente, assegurando a movimentação da planta. $\mathrm{O}$ corpo apresenta colunas retas caneladas de perfil redondo. Internamente, pilastras em formato de tronco de pirâmide ladeiam o camarim; na renda da boca da tribuna, há elementos curvilíneos em forma de "C", "S" e rocalhas; no intercolúnio, peanhas. O sacrário tem planta contracurvada, moldura recortada e ornamentos na porção superior arrematando a peça; e o trono foi alocado em caixa de base retangular, apresenta quatro degraus com curvas, contracurvas, volumes côncavos e convexos. O entablamento é em arquitrave bipartida e friso de perfil retilíneo, semelhante aos exemplares mineiros erguidos nas últimas três décadas dos setecentos, como ilustram os retábulos da nave da igreja Matriz de Nossa Senhora do Bom Sucesso, em Caeté. O registro com maior incidência de ornamentos é o coroamento inserido em arco pleno sobre respaldo côncavo, com frontões interrompidos nas extremidades, mísulas laterais sustentando sanefa com lambrequins, relevos de flores. No arremate está o brasão da Ordem Mercedária com inscrição de cruz, ladeado por elementos curvilíneos em forma de "C" e por coroa na porção superior.

No lado esquerdo da traça, foi detalhada a estrutura interna retabular e a escala, com a numeração $1,2,3,4,5,6,7,8,9,10$ (de baixo para cima), interrompida e, proporcionalmente, finalizada na parte superior com o número 20. Consta ainda a vista em corte da escada de acesso ao trono, com numeração no último degrau, provavelmente indicando o espelho. No registro do coroamento, estão arcos que sequenciam a organização do entablamento. No último deles, consta o texto "Esta he forro do Camarim". Em suma, essa fração do desenho engloba direções técnicas e medidas necessárias à confecção da peça, abrangendo detalhamento da alvenaria da igreja onde seria instalado o retábulo.

Persistem dúvidas sobre a data de preparação da traça e para qual igreja ela foi ideada, pois a ficha catalográfica correspondente não indica a região de origem, nem se foi produzida para edificação religiosa localizada em Minas Gerais ou para algum templo de outra área do território colonial lusobrasileiro. Buscou-se, neste trabalho, por meio do exame formal, extrair informações que sinalizassem a época de produção da obra, atentando-se para a configuração do risco que especifica

${ }^{12}$ Ibidem.

R. Inter. Interdisc. Art\&Sensorium, Curitiba, v.7, n.2, p. 067 - 081 Jul.- Dez. 2020 
o momento em que as peças retabulares passaram a envolver feições diferenciadas dos modelos erguidos até a década de 1760, exibindo simplificação dos elementos composicionais e ornamentais, redução (ou total ausência) das figuras antropomórficas angelicais. Tais fatos evidenciam influências do Rococó, que se fez notar desde 1760 até as duas primeiras décadas do século XIX, em Minas, como esclareceu Oliveira (2003). Espécimes retabulares afins compõem a nave da igreja de Nossa Senhora do Carmo (Ouro Preto), produzidos entre 1795 - 1813 (OLIVEIRA; CAMPOS, 2010). Eles explicitam a atenuação de relevos ornamentais, de esculturas de anjos e de meninos, esses últimos ausentes no retábulo de Nossa Senhora da Piedade, riscado e executado pelo Aleijadinho em 1807 (MENEZES, 2014).

Fortuitamente, a respeito do templo que receberia o projeto, foi localizado, na cidade de Ouro Preto, um exemplar em que a formatação estrutural e os itens ornamentais exprimem relações de equivalência ao risco em estudo. Trata-se do retábulo-mor da igreja de Nossa Senhora das Mercês de Cima que, confrontado à traça em análise, pronuncia equivalências no desenho da base, colunas, pilastras em formato de tronco de pirâmide, capiteis, peanhas, renda da boca da tribuna, sacrário e entablamento. No coroamento, as paridades são constatadas na composição de mísulas, que servem de suporte para sanefa com lambrequins, e no arremate em arco pleno, que sustenta o Brasão da Ordem Mercedária, com relevo de cruz e coroa finalizando a porção superior. No entanto, verificase que a obra retabular das Mercês difere da traça em alguns aspectos, como expressam as figuras de meninos, não existentes no desenho em análise.

Cabe frisar que o relevo de cruz no Brasão do arremate, tanto no retábulo como no desenho em exame, é correlato ao mesmo item esculpido no peito da imagem devocional de Nossa Senhora das Mercês, que integra o acervo do Museu de Arte Sacra da Matriz de Nossa Senhora do Pilar (Ouro Preto), de fatura atribuída ao Aleijadinho ${ }^{13}$. Concebida inicialmente para a igreja de São José (Ouro Preto), a escultura foi, posteriormente, transferida para a também ouro-pretana igreja de Nossa Senhora das Mercês de Cima (OLIVEIRA; SANTOS FILHO; SANTOS, 2008). Essa informação, adicionada às afinidades iconográficas e escultóricas constantes entre o brasão ostentado pela imagem e o relevo do retábulo, reitera a probabilidade de esse projeto ter sido elaborado para o referido templo.

Atenuadas as incertezas sobre o local que recebeu a proposta expressa no risco, é inescusável deliberar que as variações pontuadas entre desenho e obra executada eram comuns no universo da produção da talha. Ocorrências afins podem ser compreendidas por meio de documentação alusiva aos serviços realizados em Minas Gerais, no século XVIII, que certificam alterações ajustadas pelos entalhadores no decorrer da fatura dos trabalhos, às vezes divergentes das direções constantes na traça original. Isso ocorreu, por exemplo, no processo de efetivação do retábulo de São Miguel, da Sé de Mariana, em que o entalhador José Coelho de Noronha operou modificações para que a obra ficasse "[...] com mais galantaria e perfeição" (ARQUIVO DA CASA SETECENTISTA DE MARIANA, Códice 251 - Auto 6217, Cartório do $2^{\circ}$ ofício, fl. 33v.).

Além disso, restam interrogações sobre a autoria do risco e o nome do entalhador, ou da oficina, que executou o retábulo-mor da igreja de Nossa Senhora das Mercês. O processo de investigação transcorrido sugere dois nomes de oficiais que poderiam ser os autores desses trabalhos: o carpinteiro Manuel Francisco de Araújo e o entalhador Silvério Dias.

A vida e obra de Manuel Francisco de Araújo foram analisadas por Menezes (1978), mediante extenso levantamento de documentação histórica referente ao artífice, que identifica ser ele português, natural da Freguesia de São Salvador de Minhotões, termo de Vila de Barcelos, Arcebispado de Braga. Dentre as diversas obras em que Araújo se envolveu, quando em atividade na Capitania de Minas Gerais, está a arrematação da execução de retábulos para a igreja ouro-

\footnotetext{
${ }^{13}$ As atribuições foram proferidas por Orlando Seitas Fernandes, no ano de 1971, e por Myriam Ribeiro de Oliveira, em 1995 (OLIVEIRA; SANTOS FILHO; SANTOS, 2008).

R. Inter. Interdisc. Art\&Sensorium, Curitiba, v.7, n.2, p. 067 - 081 Jul.- Dez. 2020
} 
pretana de Nossa Senhora do Carmo, em 1784 (MARTINS, 1974). No rol das tarefas por ele efetivadas, desperta atenção a menção ao recibo de trabalho firmado com a Irmandade de Nossa Senhora das Mercês, datado de 1792, em que está registrado que Araújo recebeu quantias por “[...] riscos e condições para a fatura da obra de sua capela" (MENEZES, 1978, p. 93).

Não há especificação se os riscos supracitados, elaborados por Manuel Francisco de Araújo, destinavam-se a orientar a fatura de peças retabulares. Porém, o fato de a documentação apontar o nome da igreja das Mercês, e tendo em vista a existência do projeto em debate, possivelmente desenvolvido para o dito templo, é permissível conjecturar se foi ele o autor da traça, perante o desconhecimento de outras fontes que permitam interpor esclarecimentos a esse respeito. É singular salientar que Araújo detinha ferramentas que o potencializaria, presumivelmente, a atuar na elaboração de desenhos para a arquitetura e, até mesmo, a ornamentação. Na listagem dos bens sob sua posse, há menção a "um livro de Arquitetura" (MENEZES, 1978, p. 100), em hipótese um tratado, usualmente consultado por aqueles que se dedicavam às produções artística e arquitetônica, inclusive no território da Capitania mineira. Essa indicação é endossada pela ciência de que esses livros circularam em Minas Gerais, nos séculos XVIII e XIX, como relativizam comprovações documentais inspecionadas pela historiografia da arte (PEDROSA, 2018).

A apreciação do risco permite, igualmente, constatar a destreza do anônimo autor que efetuou com rigor técnico a representação gráfica, especificando escalas e demais informações necessárias ao procedimento de execução. Atenta-se para a redução de relevos e a inexistência de figuras antropomórficas, anjos e meninos, comumente avistados nos retábulos mineiros. Acredita-se que a supressão desses itens não esteja relacionada apenas à atenuação de ornamentos nas peças retabulares erguidas à época ${ }^{14}$, em função da repercussão do Rococó na arte religiosa lusobrasileira, mas também indica que o artífice responsável pela traça detinha domínio técnico do projeto de arquitetura, sem, no entanto, ser perito em ornamentação, como outros profissionais que se dedicavam à produção da talha. Tal inferência acentua a possibilidade de ser Manuel Francisco de Araújo o autor do risco em tela, pois sua operação em Minas estava associada ao ofício da carpintaria e de obras arquitetônicas, o que pode esclarecer a abordagem plástica escolhida para o retábulo. Nota-se que a simplificação dos motivos decorativos, frente a outros espécimes coevos, pode também externar admissíveis limitações financeiras da Irmandade de Nossa Senhora das Mercês e Misericórdia ${ }^{15}$, exigindo que fosse modesta a peça para poupar recursos em sua materialização.

Ressalvadas as direções que intentam pontuar o autor do projeto, deve-se conjecturar o responsável por sua fatura, uma vez que a documentação identificada não ilustra essa inquirição. Em meio aos parcos registros conhecidos, são curiosos os pagamentos referentes a trabalhos prestados pelo entalhador Silvério Dias, na igreja de Nossa Senhora das Mercês, em 1805-1806 (MARTINS, 1974). As quantias foram recebidas por Dona Anna Pulcheria, pois Silvério era escravo e estava sob seu controle (MARTINS, 1974). Não foram enumerados os afazeres cumpridos por Dias, e a sequência de recibos, por obrigações processadas no mesmo templo, avançaram até o ano de 1811 (MARTINS, 1974). Ciente de sua ocupação, despontam indagações sobre ter sido Silvério Dias o encarregado pela confecção do retábulo-mor. As incertezas a esse respeito são salientadas em virtude do entalhador Manoel Gonçalves Bragança ter executado, em 1810, a fatura da portada da igreja das Mercês e Misericórdia (MARTINS, 1974). Apesar de especificada a atividade empreendida, em um ambiente embebecido por imprecisões documentais, é prudente, por ser conhecida a profissão de Bragança, questionar se ele auxiliou a fábrica do retábulo-mor. Caso venha a ser comprovada a proposição de Silvério Dias ser o oficial que consumou a peça retabular em

\footnotetext{
${ }^{14}$ Exemplo: retábulos da nave da igreja de Nossa Senhora do Carmo, em Ouro Preto.

${ }^{15}$ Conforme pesquisas de Oliveira, a Irmandade de Nossa Senhora das Mercês de Ouro Preto surgiu em 1754 e, na década de 1760, dividiu-se em dois grupos: Irmandade de Nossa Senhora das Mercês e Perdões, e a Irmandade de Nossa Senhora das Mercês e Misericórdia (Mercês de Cima), que congregava afrodescendentes nascidos no Brasil (OLIVEIRA, 2010).
}

R. Inter. Interdisc. Art\&Sensorium, Curitiba, v.7, n.2, p. 067 - 081 Jul.- Dez. 2020 
pauta $^{16}$, com ou sem a colaboração de Manoel Gonçalves Bragança, é admissível sugerir ter sido ela produzida na primeira década do século XIX, consoante as datas em que Dias se encontrava na edificação, em função de contratos a cumprir.

Lamentavelmente, são irrisórias as informações relativas a Silvério Dias e Manoel Gonçalves Bragança. É sabido que Dias era natural de Mariana, foi aprendiz do entalhador Francisco Vieira Servas, durante sete anos, e as despesas de seu aprendizado foram custeadas por Dona Anna Pucheria ${ }^{17}$. Sobre Bragança, Martins (1974) descreveu que ele era pardo e residiu em Ouro Preto, onde faleceu no dia 19 de fevereiro de 1820. Deixou trabalhos no Santuário do Bom Jesus do Matosinhos (Congonhas), na igreja das Mercês (Ouro Preto) e na igreja de São Francisco de Assis (Ouro Preto) (MARTINS, 1974). Para traçar direções seguras a respeito das asserções apreciadas, é imprescindível organizar levantamentos sobre a atuação de Silvério Dias e de Manoel Gonçalves Bragança, em proveito de explanar se ambos estiveram relacionados à confecção do retábulo-mor da igreja de Nossa Senhora das Mercês, especialmente porque são pouco os examinados casos, em Minas Gerais, de escravos e mulatos envolvidos em obras artísticas. Essa lacuna continua submersa em dúvidas ocasionadas pela escassez de pesquisas.

\section{O desenho para o dossel e para o castiçal: alguma análise}

Analisado o risco para retábulo-mor, compete explorar o segundo desenho anunciado, também pertencente ao acervo do Museu da Inconfidência, que ilustra um dossel ${ }^{18}$. Apurou-se a existência de inscrições constantes na peça, mencionando como destino a igreja ouro-pretana de Nossa Senhora das Dores: "Dores de V R.ca - 6 de mayo de 809" 19 . O suporte em papel mede $31,5 \mathrm{~cm}$ de altura por $22 \mathrm{~cm}$ de largura; a imagem foi traçada com tinta nanquim; há indicação de escala lateral com números $1,2,3,4,5,6,7$ e, na porção superior, 1,2,3,4,5 separando os tramos verticais; linhas horizontais dividem proporcionalmente a peça, esclarecendo referências imprescindíveis para desenvolver a traça e os métodos de construção para subsequente produção da obra. A autoria é ausente, característica verificável em outros itens similares, o que dificulta conhecer o nome dos oficiais que se dedicavam a elaborar esses desenhos. O risco apresenta dossel com lambrequins, pináculo no arremate e, nas laterais, duas figuras antropomórficas aladas que afastam o cortinado pendente do dossel, esboçadas com expressão e gestualidade diferentes, eliminando o convencional tratamento simétrico de trabalhos coevos correspondentes (Figura 2).

\footnotetext{
${ }^{16}$ Conjectura passível de comprovação se for encontrado documento que ateste a sugestão ou caso seja realizada análise comparativa com outro trabalho de talha confeccionado por Silvério Dias.

${ }^{17}$ Ação do libelo cível e crime: Autora D. Ana Puquéria de Siqueira, Réu, Revd. ${ }^{\circ}$ D. Pereira de Santa Apolônia, “Autos de cobrança", maço no 14, arquivo da Cúria de Mariana) (MARTINS, 1974, v. 1, p. 246).

18 MUSEU DA INCONFIDÊNCIA. Dossel para a igreja Nossa Senhora das Dores, Ouro Preto. Ouro Preto. Disponível em: <http://museudainconfidencia.acervos.museus.gov.br/acervo-museologico/desenho-arquitetonico-6/> . Acesso em: 20 abr. 2020.

${ }^{19}$ Ibidem.
}

R. Inter. Interdisc. Art\&Sensorium, Curitiba, v.7, n.2, p. 067 - 081 Jul.- Dez. 2020 


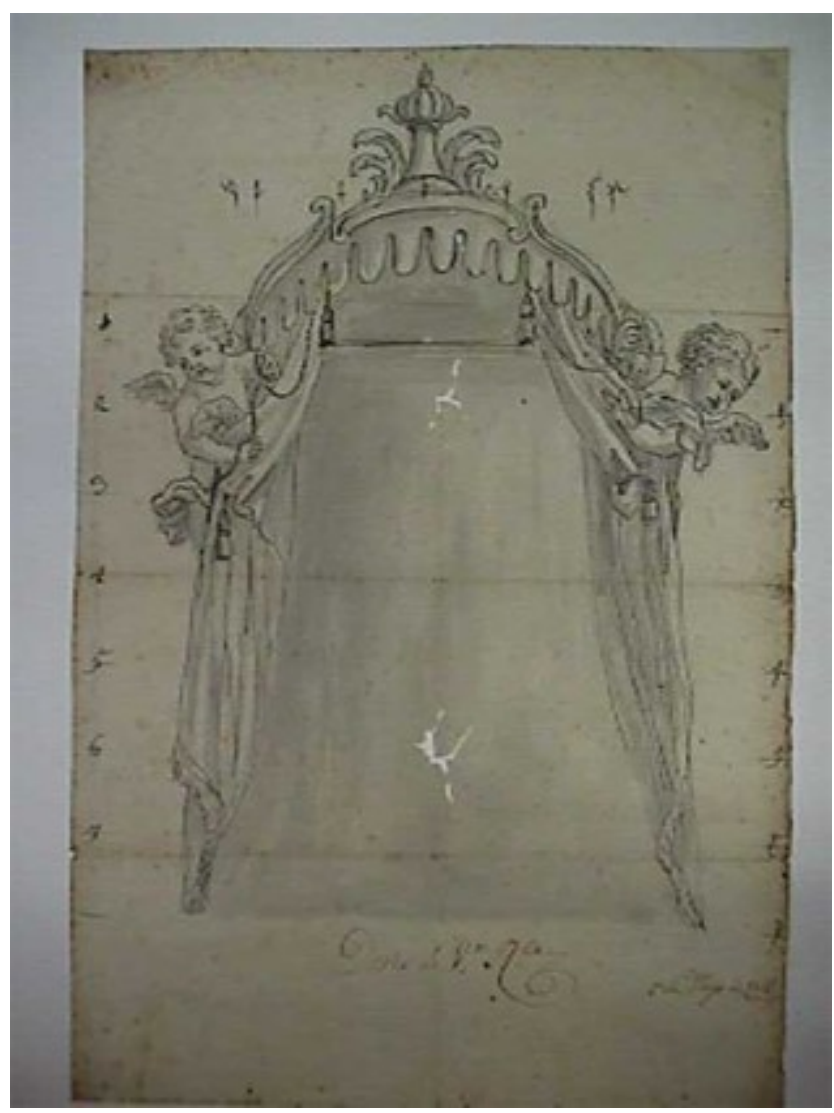

Figura 2 - Risco dossel para a igreja Nossa Senhora das Dores, Ouro Preto. Fonte: Museu da Inconfidência, Ouro Preto. ${ }^{20}$

As pontuais informações inseridas no projeto indicam como destino a capela de Nossa Senhora das Dores (Ouro Preto), mas não mencionam se ele serviria para integrar construção retabular, algum espaço específico do templo ou se seria utilizado como cenografia efêmera, em celebrações e festejos organizados pelas irmandades sediadas na edificação. Vestígios da peça não foram identificados e é impreciso afirmar se ela foi ou não componente de um retábulo, pois essa alegação exigiria localizar as unidades que fazem sua complementação e sua sustentação, como colunas e pilastras, por exemplo, ou encontrar esboços que contenham os demais elementos de um provável conjunto. As dificuldades para compreensão do caso são acentuadas perante a inexpressividade de registros e de estudos sobre a capela, inicialmente erguida em pau-a-pique, no ano de 1783 (LEMOS, 2016), e reconstruída entre 1835-1850 (OLIVEIRA; CAMPOS, 2010). Sobre a trajetória histórica, são ausentes quaisquer notícias pormenorizadas que consintam compreender a que se destinava o risco em exame. Ainda que sejam insuficientes outras informações, reconhece-se ser o desenho importante registro sobre a produção de esboços para a arte religiosa na Capitania de Minas Gerais.

\footnotetext{
${ }^{20}$ Ibidem.
} 


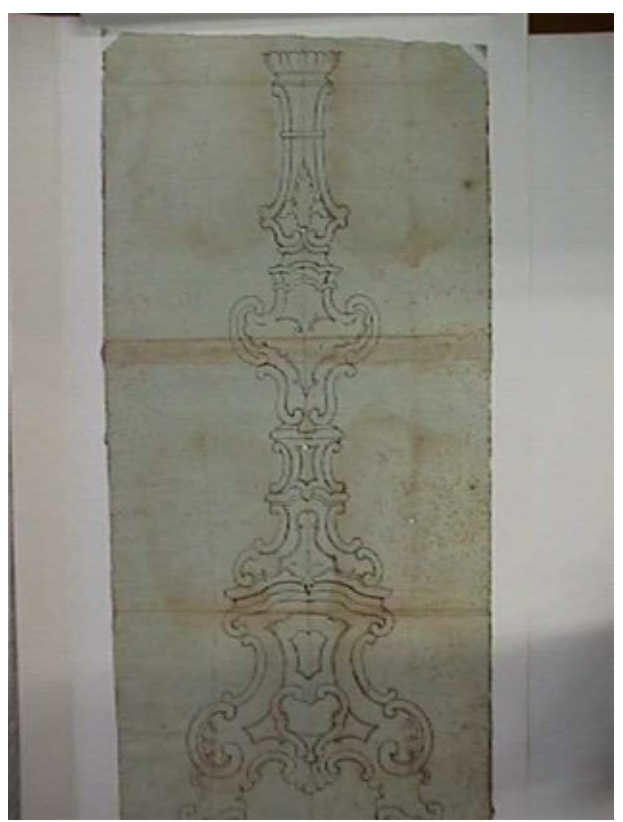

Figura 3 - Risco para castiçal.

Fonte: Museu da Inconfidência, Ouro Preto. ${ }^{21}$

Nesse contexto, encontra-se também o desenho para castiçal que integra o acervo do Museu da Inconfidência ${ }^{22}$. O risco foi elaborado com tinta nanquim, em suporte de papel de $66,4 \mathrm{~cm}$ de altura por $31,3 \mathrm{~cm}$ de largura. A opção pelo uso de escala natural evidencia as reais proporções do objeto representado em vista frontal, facultada a supressão das demais projeções, porque os castiçais apresentavam, geralmente, o mesmo feitio em todos os três lados. A traça foi delineada por entrelaças de curvas e contracurvas em forma de "C" e " $\mathrm{S}$ ", estruturando a peça (Figura 3). São ausentes detalhes sobre data, autoria e destino da obra.

Sublinha-se que traça idêntica está registrada, também, no Arquivo Central do Instituto do Patrimônio Histórico e Artístico Nacional - IPHAN (Rio de Janeiro) ${ }^{23}$, discernida como item oriundo da igreja de São Francisco de Assis (Ouro Preto) e sem designações de data e de autoria. Apesar de a documentação não afirmar qual é a imagem original e qual é a reprodução, os aspectos das fotografias disponibilizadas pela Central do IPHAN, do Rio de Janeiro, e pelo Museu da Inconfidência permitem sugerir que essa última instituição tem sob sua guarda a fonte primária. Resguardadas essas particularidades, não há dúvidas de que ambas as representações sejam o mesmo risco e, consoante a informação apurada, presumivelmente gizada para a igreja de São Francisco de Assis (Ouro Preto). Como são inexistentes registros adicionais para avançar as explanações sobre o caso, é urgente averiguar se, entre os objetos litúrgicos do supracitado templo ouro-pretano, não expostos atualmente, há algum castiçal com as características da ilustração comentada.

A questão mais incitadora no estudo dessa traça é a existência, no Arquivo Central do IPHAN (Rio de Janeiro), de uma imagem detalhada do mesmo castiçal ${ }^{24}$, cadastrada como procedente da igreja de São Francisco de Assis (Ouro Preto). A confrontação do risco pertencente ao Museu da

21 MUSEU DA INCONFIDÊNCIA. Risco Castiçal. Ouro Preto. Disponível em: < http://museudainconfidencia.acervos.museus.gov.br/acervo-museologico/desenho-documental/>. Acesso em: 20 abr. 2020.

${ }^{22}$ Ibidem.

${ }^{23}$ ARQUIVO CENTRAL DO INSTITUTO DO PATRIMÔNIO HISTÓRICO E ARTÍSTICO NACIONAL - SEÇÃO RIO DE JANEIRO. Rede de Arquivos do IPHAN. Desenho de Castiçal: Igreja de São Francisco de Assis, Ouro Preto. Disponível em: <http://acervodigital.iphan.gov.br> Acesso em: 5 mai. 2020.

${ }^{24}$ É compreensível se tratar de cópia reproduzida a partir de fonte primária não identificada.

R. Inter. Interdisc. Art\&Sensorium, Curitiba, v.7, n.2, p. 067 - 081 Jul.- Dez. 2020 
Inconfidência (Figura 3) com o desenho citado (Figura 4) ${ }^{25}$, em que o sombreamento realçou os detalhes formais, conferindo-lhe o aspecto tridimensional, elucida que seja a mesma peça, excetuando-se uma pequena distinção entre elas, constante no arremate superior. Na presença de irresoluções para o fato, questiona-se: o desenho detalhado (Figura 4) foi um trabalho empreendido no ímpeto da elaboração do risco frontal (Figura 3) ou um material gizado, posteriormente, por alguém que encontrou o primeiro esboço? Essa indefinição ainda perdura sem solução.

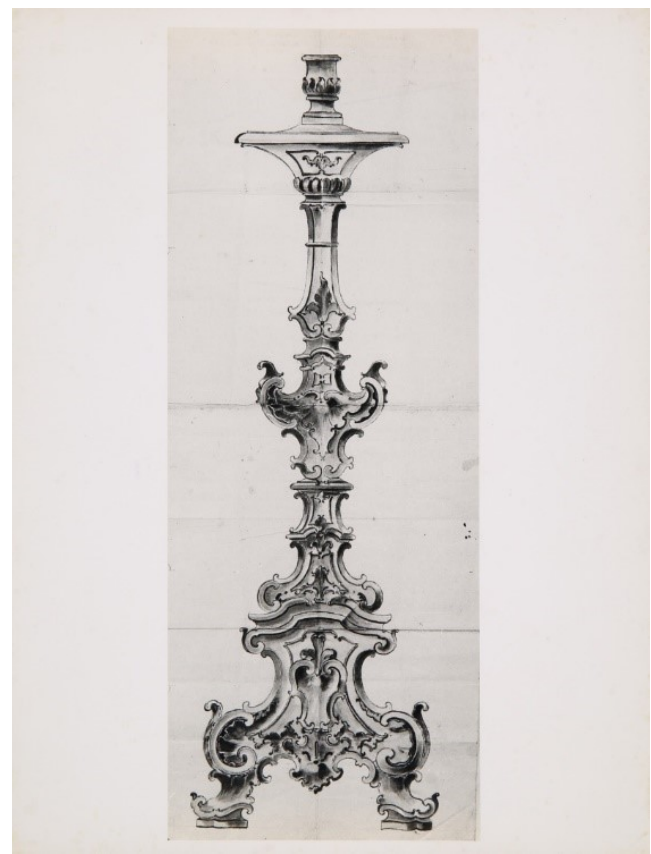

Figura 4 - Desenho castiçal.

Fonte: Acervo Digital IPHAN - Seção Rio de Janeiro. ${ }^{26}$

Os castiçais são itens litúrgicos necessários à realização do culto e existem às centenas nas igrejas mineiras, compondo as banquetas dos retábulos. A produção desses artigos, em Minas, exigiu a operação de oficiais escultores, entalhadores e carpinteiros, pois eles eram massivamente confeccionados em madeira, embora sejam conhecidos diversos exemplares em prata, como comprova o conjunto da igreja Matriz de Santo Antônio (Tiradentes) e os itens que compõem o Museu de Arte Sacra da Matriz de Nossa Senhora do Pilar (Ouro Preto) ${ }^{27}$. Legitima a assertiva anterior a operação do entalhador Felipe Vieira, notável profissional envolvido na constituição da talha mineira setecentista que, em 1767, recebeu quantias por faturar castiçais para a igreja ouropretana de Santa Efigênia ${ }^{28}$.

Além do entalhador supracitado, há registros de outros profissionais produzindo essas peças, salientando-se os carpinteiros Antônio Pereira da Costa, Pedro Machado Toledo e Romão de Abreu que confeccionaram castiçais para templos da cidade de Mariana. O primeiro recebeu por "feitio de 3 dúzias de castiçais" para a igreja de Nossa Senhora das Mercês (MARTINS, 1974, v. 1, p. 201); Pedro Machado Toledo, no ano de 1794, foi merecedor de valores por "feitio de 50 castisais torniados" para a igreja de São Francisco de Assis (MARTINS, 1974, v. 2, p. 287); e Romão de

${ }^{25}$ ARQUIVO CENTRAL DO INSTITUTO DO PATRIMÔNIO HISTÓRICO E ARTÍSTICO NACIONAL - SEÇÃO RIO DE JANEIRO. Rede de Arquivos do IPHAN. Desenho de Castiçal: Igreja de São Francisco de Assis, Ouro Preto. Disponível em: < http://acervodigital.iphan.gov.br> Acesso em: 5 mai. 2020.

${ }^{26}$ Ibidem.

${ }^{27}$ Consoante Pedrosa (2019), foi comum, em Minas Gerais, a aquisição de castiçais de prata no Rio de Janeiro e, até mesmo, em Lisboa.

${ }^{28}$ CENTRO DE ESTUDOS DO CICLO DO OURO. Livro de Receitas e Despesas da Irmandade do Rosário dos Pretos de Ouro Preto, 1723-1798, v. 132, fl. 91.

R. Inter. Interdisc. Art\&Sensorium, Curitiba, v.7, n.2, p. 067 - 081 Jul.- Dez. 2020 
Abreu auferiu importâncias por "feitio de seis castiçais" para a igreja de Nossa Senhora do Carmo (MARTINS, 1974, v. 1, p. 12). Outro exemplo conhecido envolve o Aleijadinho. Em 1808, ele executou castiçais para o Santuário do Bom Jesus do Matosinhos, em Congonhas (MENZES, 2014).

A expressiva existência de castiçais nas igrejas de Minas reclama que o tema seja intento de profundo estudo, capaz de pontuar os nomes dos homens envolvidos nos processos de criação e de confecção dessas obras, os temas utilizados para inspirar relevos e, até mesmo, averiguar se a construção formal desses artigos estabelecia diálogo com a constituição plástica do retábulo para o qual eram concebidos, visando harmonizar o conjunto. Nesse espectro está imerso o desconhecimento historiográfico sobre a atuação de oficiais, em Minas Gerais, dedicados a riscar tais objetos, diluindo-se, assim, tentativas que permitam apontar o autor do desenho em exame ${ }^{29}$.

Cabe frisar que estudos dedicados a examinar os castiçais encontrados nos templos mineiros, imprescindivelmente, devem investigar as fontes que serviram para referenciar formas e motivos iconográficos ostentados nesses artigos, de modo que permitam explicitar as preferências plásticas dominantes no período em que foram concebidos, pois o exame do risco encontrado esclarece repercussões das influências do Rococó, marcadamente presente na talha setecentista e oitocentista de Minas Gerais. Nesse sentido, urge verificar se essas peças foram inspiradas em gravuras, estampas e demais impressos circulantes à época, cuja presença na Capitania de Minas foi verificada por Bohrer (2007), Silva (2012) e Pedrosa (2019), autores que avaliaram a repercussão do repertório extraído dessas fontes, que auxiliaram a produção da pintura e da talha local.

\section{Considerações finais}

A orientação basilar deste artigo foi apresentar três riscos para talha que, pela temática e pela raridade, são resquícios elementares para a história da arte colonial luso-brasileira. Tais projetos, elencados em registros coetâneos que formalizavam os processos de produção da escultura ornamental em Minas Gerais, antecediam procedimentos de preparação do trabalho e visavam instruir sua execução. Apesar disso, esses documentos são inexistentes nos arquivos, salvo parcas exceções, somando cerca de uma dezena de exemplares. As omissões sobre a matéria podem ser compreendidas pelo fato de esses desenhos ficarem sob a posse dos profissionais envolvidos na efetivação das atividades, descartados depois da louvação, quando periciado e confrontado o item faturado com o risco e os demais apontamentos destinados a conduzir o cumprimento do acordo firmado no ato de arrematação das obras (PEDROSA, 2019). A outra hipótese, para o desaparecimento dessas traças, é ancorada na análise de Bazin (1982), que demonstrou ser a concepção intelectual do projeto, dentre as diversas atribuições cumpridas pelos oficiais dedicados à arte da talha mineira, a porção menos lucrativa. Os vestígios revelam que eles auferiam pequenas quantias por essas incumbências, o que justificaria a minguada valorização desses afazeres e, até mesmo, o desaparecimento das traças dos espólios dos arquivos.

No tocante às peças examinadas, persistem hiatos referentes aos nomes dos oficiais que as riscaram e ao destino final do castiçal e do dossel para a capela de Nossa Senhora das Dores (Ouro Preto), pois não foi possível distinguir se eles estão alocados em algum templo. Incertezas afins mediavam o entendimento do risco retabular, mas, a partir da investigação empreendida neste artigo, foi constatada a viabilidade de ser esse o desenho que subsidiou a fatura do retábulo-mor da igreja ouro-pretana de Nossa Senhora das Mercês de Cima. Porém, sobre essa peça resta esquadrinhar, exaustivamente, a identidade dos artífices responsáveis pelo risco e execução, atentando-se para as conjecturas levantadas que indicariam Manoel Francisco de Araújo e Silvério Dias, respectivamente, como os homens à frente desses trabalhos.

\footnotetext{
${ }^{29}$ A partir desse conhecimento é questionável se o profissional que faturava o castiçal também poderia ser o responsável por seu desenho.
}

R. Inter. Interdisc. Art\&Sensorium, Curitiba, v.7, n.2, p. 067 - 081 Jul.- Dez. 2020 
Ressalvados esses apontamentos, é fundamental assinalar a importância de se reavaliar, em pesquisas futuras, o conteúdo explorado neste texto, pois as discussões empreendidas não responderam às diversas indagações afloradas ao se explorar a orbe do projeto de talha no Brasil colonial, que permanece insuficientemente apurada. Dentre esses aspectos, registra-se a exiguidade, ou total inexistência, de estudos sobre os castiçais concebidos para os templos de Minas Gerais, entre os séculos XVIII e XIX. Esses objetos litúrgicos são dotados de elementos formais, estilísticos, iconográficos e simbólicos suscetíveis de narrar fração fundamental da história da arte local, pois evidenciam a assimilação das influências artísticas que afetavam a elaboração da ornamentação religiosa na região e, do mesmo modo, a colaboração de oficiais afeitos a esculpir a madeira, cuja atuação na confecção de castiçais ainda é desconhecida.

Por fim, julga-se necessário o prosseguimento das pesquisas em prol de se examinar as prováveis relações das peças apresentadas com os exemplares encontrados em igrejas brasileiras e portuguesas, incluindo-se nesse estudo a avaliação de modelos, gravuras, tratados de arquitetura e demais fontes que possam ter exercido influência nas escolhas pontuadas nos desenhos apresentados.

\section{Referências}

ARQUIVO CENTRAL DO INSTITUTO DO PATRIMÔNIO HISTÓRICO E ARTÍSTICO NACIONAL - SEÇÃO RIO DE JANEIRO. Rede de Arquivos do IPHAN. Desenho de Castiçal: Igreja de São Francisco de Assis, Ouro Preto. Disponível em: <http://acervodigital.iphan.gov.br> Acesso em: 5 mai. 2020.

ARQUIVO DA CASA SETECENTISTA DE MARIANA - Ações cíveis. Códice 251 - Auto 6217 , Cartório do $2^{\circ}$ ofício.

ARQUIVO DA PARÓQUIA DE NOSSA SENHORA DO PILAR. Livro de Termos da Irmandade do Santíssimo Sacramento, 1729-1777, v. 224.

ARQUIVO HISTÓRICO ULTRAMARINO: Instituto de Investigação Científica Tropical. Minas Gerais, PT/AHU/CARTM/011/01168.

ARQUIVO PÚBLICO MINEIRO. Livro de arrematações de contratos e ofícios públicos a cargo da Provedoria da Real Fazenda em Vila Rica (1744-1765). Casa dos Contos. Códice 1075.

ÁVILA, Affonso; GONTIJO, João Marcos Machado; MACHADO, Reinaldo Guedes FUNDAÇÃO JOÃO PINHEIRO. Barroco mineiro: glossário de arquitetura e ornamentação. Belo Horizonte: Fundação João Pinheiro, 1996.

BAZIN, Germain. A Arquitetura Religiosa Barroca no Brasil. Rio de Janeiro: Record, 2v., 1983.

BOHRER, Alex Fernandes. Os diálogos de Fênix: fontes iconográficas, mecenato e circularidade no barroco mineiro. Dissertação (Mestrado em História Social da Cultura). Faculdade de Filosofia e Ciências Humanas, Universidade Federal de Minas Gerais, Belo Horizonte, 2007.

BOHRER, Alex Fernandes. A Talha do Estilo Nacional Português em Minas Gerais: contexto sociocultural e produção artística. 2015. 2 v. Tese (Doutorado em História). FAFICH, Universidade Federal de Minas Gerais, Belo Horizonte, 2015.

CENTRO DE ESTUDOS DO CICLO DO OURO. Livro de Receitas e Despesas da Irmandade do Rosário dos Pretos de Ouro Preto, 1723-1798, v. 132.

GUTIERREZ, Angela; RAMOS, Adriano. Francisco Vieira Servas e o ofício da escultura na capitania das minas do ouro. Belo Horizonte: Instituto Cultural Flávio Gutierrez, 2002. 
GUTIERREZ, Rodrigo Luiz Minot. Estudo sobre as representações e o processo de produção da arquitetura colonial em Ouro Preto no século XVIII: risco debuxado na parede da capela do Carmo de Ouro Preto. Dissertação (Mestrado em Tecnologia da Arquitetura). Faculdade de Arquitetura e Urbanismo, Universidade de São Paulo, São Paulo, 2016.

LEMOS, Paulo. (org.). Ouro Preto: Igrejas Capelas; Churches and Chapels. Églises et Chapelles. Ouro Preto: Ouro Preto Editora, 2016.

MARTINS, Judith. Dicionário de artistas e artífices dos séculos XVIII e XIX em Minas Gerais. Rio de Janeiro, Publicações da Diretoria do Patrimônio Histórico e Artístico Nacional, nº 27, 2 v., 1974.

MENEZES, Ivo Porto de. Manoel Francisco de Araújo. Revista do Patrimônio Histórico e Artístico Nacional, n.18, p. 83-113, 1978.

MENEZES, Ivo Porto de. Antônio Francisco Lisboa. Belo Horizonte: C/Arte, 2014.

MUSEU DA INCONFIDÊNCIA. Desenho Arquitetônico. Ouro Preto. Disponível em: $<$ http://museudainconfidencia.acervos.museus.gov.br/acervo-museologico/desenho-arquitetonico5/>. Acesso em: 20 abr. 2020.

MUSEU DA INCONFIDÊNCIA. Dossel para a igreja Nossa Senhora das Dores, Ouro Preto. Ouro Preto. Disponível em: $<\mathrm{http}: / /$ museudainconfidencia.acervos.museus.gov.br/acervomuseologico/desenho-arquitetonico-6/>. Acesso em: 20 abr. 2020.

MUSEU DA INCONFIDÊNCIA. Risco Castiçal. Ouro Preto. Disponível em: $<$ http://museudainconfidencia.acervos.museus.gov.br/acervo-museologico/desenho-documental/>. Acesso em: 20 abr. 2020.

OLIVEIRA, Marcelo Almeida. Igreja de Nossa Senhora das Mercês e Misericórdia em Ouro Preto: religiosidade e rivalidade nas Minas Setecentistas. In: FERREIRA-ALVES, Natália Marinho (Org.). A Misericórdia de Vila Real e as Misericórdias no Mundo de Expressão Portuguesa. Porto: Centro de Estudos da População, Economia e Sociedade, 2010, p. 421-440.

OLIVEIRA, Myriam Andrade Ribeiro de. O Rococó religioso no Brasil e seus antecedentes europeus. São Paulo: Cosac e Naify, 2003.

OLIVEIRA, Myriam Andrade Ribeiro de; SANTOS FILHO, Olinto Rodrigues dos; SANTOS, Antônio Fernando Batista dos. O Aleijadinho e sua oficina: catálogo das esculturas devocionais. 2 ed. Rio de Janeiro: Capivara, 2008.

OLIVEIRA, Myriam Andrade Ribeiro de; CAMPOS, Adalgisa Arantes. Barroco e rococó nas igrejas de Ouro Preto e Mariana. Brasília: Instituto do Patrimônio Histórico e Artístico Nacional: Monumenta, 2v. 2010.

PEDROSA, Aziz José de Oliveira. Uma Oficina de talha na Sé de Mariana: o fazer artístico e o contrato de trabalho. Varia História, Belo Horizonte, v. 29, n. 50, p. 597-631, maio/agosto de 2013.

PEDROSA, Aziz José de Oliveira. Modelos, formas e referências para os retábulos em Minas Gerais: o caso do tratado de Andrea Pozzo. Revista Autônoma, Madri, 13, p. 103-124, 2018.

PEDROSA, Aziz José de Oliveira. A produção da talha joanina na Capitania de Minas Gerais: retábulos, entalhadores e oficinas. Belo Horizonte: Editora UFMG, 2019.

RODRIGUES, Francisco de Assis. Diccionario Technico e Historico de Pintura, Esculptura, Architectura e Gravura. Lisboa: Imprensa Nacional, 1876.

SILVA, Mateus Alves. O tratado de Andrea Pozzo e a pintura de perspectiva em Minas Gerais. Dissertação (Mestrado em História Social da Cultura). Faculdade de Filosofia e Ciências Humanas, Universidade Federal de Minas Gerais, Belo Horizonte, 2012. 